\title{
To ping or not to ping: the use of active acoustic devices in mitigating interactions between small cetaceans and gillnet fisheries
}

\author{
Stephen M. Dawson ${ }^{1, *}$ Simon Northridge ${ }^{2}$, Danielle Waples ${ }^{3}$, Andrew J Read ${ }^{3}$ \\ ${ }^{1}$ Department of Marine Science, University of Otago, 310 Castle Street, Dunedin, New Zealand \\ ${ }^{2}$ Sea Mammal Research Unit, University of St Andrews, St Andrews, Fife KY16 8LB, UK \\ ${ }^{3}$ Division of Marine Science and Conservation, Nicholas School of the Environment, Duke University, \\ 135 Duke Marine Lab Road, Beaufort, North Carolina 28516, USA
}

\begin{abstract}
Active sound emitters ('pingers') are used in several gillnet fisheries to reduce bycatch of small cetaceans, and/or to reduce depredation by dolphins. Here, we review studies conducted to determine how effective these devices may be as management tools. Significant reductions in bycatch of harbour porpoise Phocoena phocoena, franciscana Pontoporia blainvillei, common Delphinus delphis and striped dolphin Stenella coeruleoalba, and beaked whales as a group have been demonstrated. For harbour porpoise this result has been replicated in 14 controlled experiments in North America and Europe, and appears to be due to porpoises avoiding the area ensonified by pingers. Two gillnet fisheries (California-Oregon driftnet fishery for swordfish; New England groundfish fishery) with mandatory pinger use have been studied for over a decade. Bycatch rates of dolphins/porpoises have fallen by 50 to $60 \%$, and there is no evidence of bycatch increasing over time due to habituation. In both fisheries, bycatch rates were significantly higher in nets sparsely equipped with pingers or in which pingers had failed, than in nets without any pingers at all. Studies of pinger use to reduce depredation by bottlenose dolphins Tursiops truncatus generally show small and inconsistent improvements in fish catches and somewhat reduced net damage. Dolphin bycatch in these fisheries is rare, but still occurs in nets with pingers. Taken together, these studies suggest that the most promising candidates for bycatch reduction via pinger use will be gillnet fisheries in developed countries in which the bycaught cetaceans are generally neophobic species with large home ranges. We offer a set of lessons learned from the last decade of bycatch management.
\end{abstract}

KEY WORDS: Gillnet $\cdot$ Bycatch $\cdot$ Dolphin $\cdot$ Porpoise $\cdot$ Pinger $\cdot$ Acoustic devices

\section{INTRODUCTION}

Three fundamentally different approaches exist to mitigate deleterious interactions between humans and wildlife. The first is to mandate a change in human behaviour or to create a climate in which such changes are made voluntarily. The second is to modify the nature of the interaction by the introduction of technology. The third, and most challenging, is to change the behaviour of the animals themselves, without requiring commensurate changes in human behaviour. For example, consider the problem of collisions between birds and aircraft, also known as bird strikes. The first approach might entail requiring a change to flight paths or landing times, such as landing at night when many birds are inactive. The sec- 
ond could involve modifications to the intake of aircraft engines to reduce the likelihood of failure in case of a bird strike. The last option would attempt to modify the behaviour or distribution of the birds themselves through harassment or other means to reduce the likelihood of a collision.

In this paper, we explore an example of the third approach described above: the use of acoustic pingers to modify the behaviour of dolphins, porpoises and small whales to reduce the frequency of their interactions with gillnet ${ }^{\underline{1}}$ fisheries. The incidental mortality of small cetaceans in such fisheries is the most pressing threat to the global conservation of these marine mammals (Brownell et al. 1989, Read et al. 2006). All 3 of the approaches described above have been used to address this conservation problem, including: changing human behaviour through time-area fishery closures (e.g. Dawson \& Slooten 1993, Murray et al. 2000), technological modifications to the fishing gear (e.g. Hembree \& Harwood 1987, Trippel et al. 2003) and the use of active sound emitters or acoustic 'alarms' (here referred to as pingers) to reduce the likelihood of entanglement by modifying the behaviour of the animals themselves (e.g. Kraus et al. 1997). These approaches are sometimes used in combination (e.g. area closures and pingers, Palka et al. 2008; modification to float line depth and pingers, Barlow \& Cameron 2003). Nevertheless, the use of pingers is attractive to fishermen (under certain conditions) because it does not require substantial changes to fishing behaviour or gear and, thus, is perceived as less costly than alternative approaches.

Active sound emitters have been used primarily in 2 contexts with marine mammals: (1) to reduce incidental mortality of dolphins and porpoises in fishing gear, known as bycatch; and (2) to reduce the economic cost of dolphins removing or damaging caught fish, known as depredation. Previous reviews (e.g. Reeves et al. 2001) considered 2 broad categories of sound emitters, the first to address the problem of bycatch and the second to mitigate depredation. Devices in the first category emit relatively low intensity sounds $(<150 \mathrm{~dB} \text { re } 1 \mu \mathrm{Pa} \text { at } 1 \mathrm{~m})^{\underline{2}}$; these are known as pingers or acoustic deterrent devices (ADDs). The second category is comprised of relatively high output emitters (>185 dB), often termed acoustic harassment devices (AHDs). The latter

${ }^{1}$ Gillnet is meant here generically, including all static entangling nets, including trammel nets.

${ }^{2}$ All source levels in this paper are referenced to $1 \mu \mathrm{Pa}$ at $1 \mathrm{~m}$ devices were originally designed to deter pinnipeds from mariculture operations and have been used widely by the aquaculture industry (Johnston \& Woodley 1998, Quick et al. 2004). AHDs were initially designed to cause discomfort or pain when an animal approaches closely.

Widespread concerns about depredation by small cetaceans in a variety of fisheries (reviewed in Read 2008) have resulted in the use of devices with intermediate output levels becoming more common in commercial fisheries. Thus, the range of available active sound emitters no longer falls into 2 discrete categories but is more of a continuum (Table 1). Many mid-range devices are designed to deter depredation of static fishing gear by coastal bottlenose dolphins Tursiops truncatus (see Table 1), but some have also been designed or used to deter capture of pelagic dolphins in mid-water trawls (e.g. DDD03, Cetasaver; Table 1).

We focus here on the use of acoustic devices to reduce bycatch of small cetaceans in static fishing gear, primarily gillnets. We focus on gillnets because bycatch in this type of gear is widely considered the most important threat to populations of small cetaceans (Read et al. 2006). Bycatch in gillnets is the primary conservation issue for the 2 most endangered small cetaceans, the vaquita Phocoena sinus (RojasBracho et al. 2006) and Maui's dolphin Cephalorhynchus hectori maui (Slooten et al. 2006). In addition, bycatch is known to threaten several other populations (e.g. franciscana Pontoporia blainvillei, Secchi \& Wang 2002; Hector's dolphin Cephalorhynchus hectori, Slooten et al. 2000; Baltic harbour porpoises Phocoena phocoena, Berggren et al. 2002). Considering that small cetaceans use sound both for communication and echolocation, it is not surprising that acoustic devices have been explored as a tool for reducing bycatch. Indeed, the use of pingers has been considered or adopted as a conservation measure for each of the above species and many others.

In this review we consider only the small, batterypowered pingers that can be attached directly to gillnets. We have not considered other acoustic deterrent practices such as the use of percussion tubes or pipes to keep animals away from gillnets and other gears (e.g. Kasuya 1985, Zahri et al. 2004), nor any methods involving playbacks of deterrent noises such as killer whale calls (Fish \& Vania 1971, ICES 2010).

Our purpose is to provide a comprehensive review of the use of pingers as tools to reduce bycatch of small cetaceans in gillnet fisheries. We review 4 types of studies: (1) controlled experiments in com- 


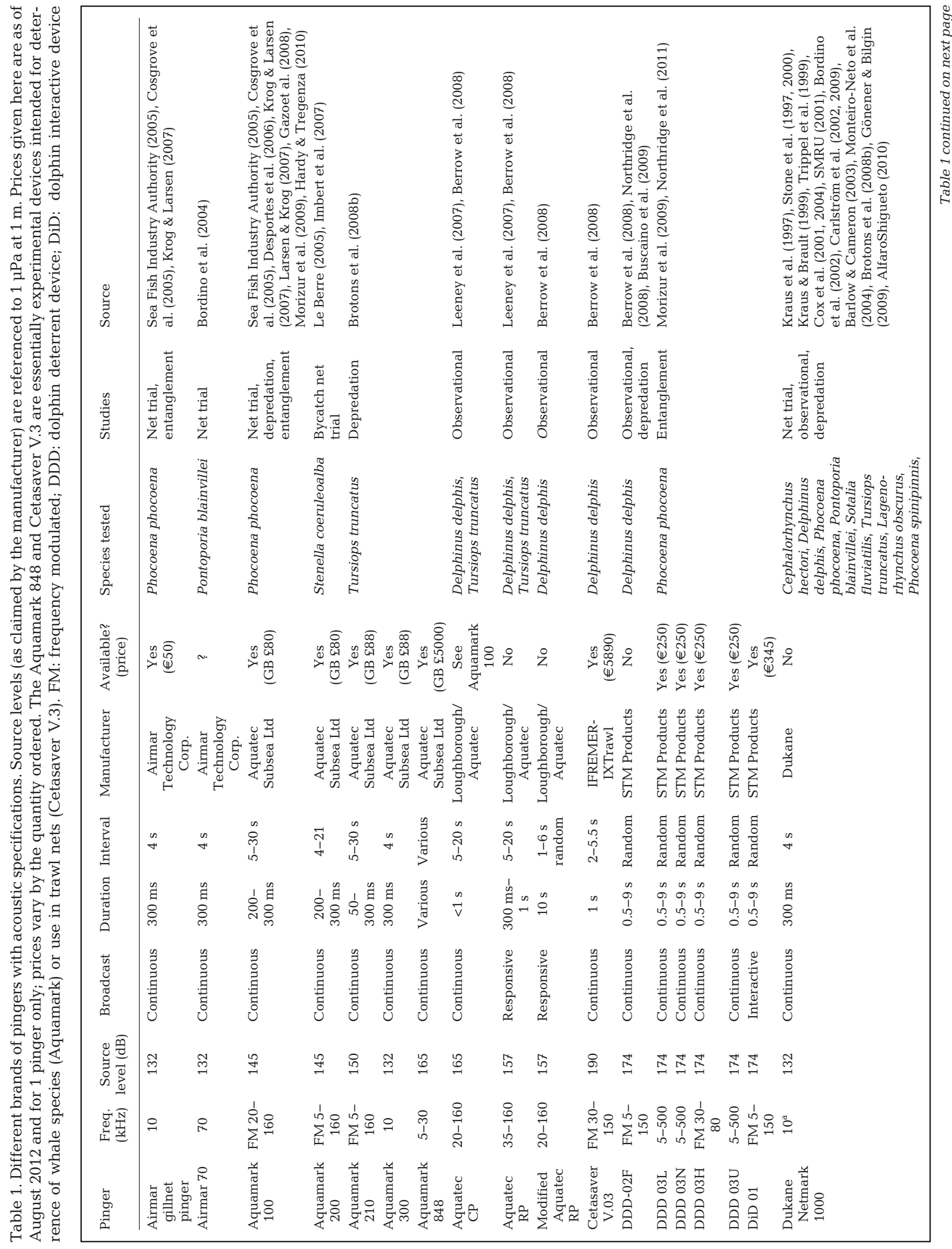




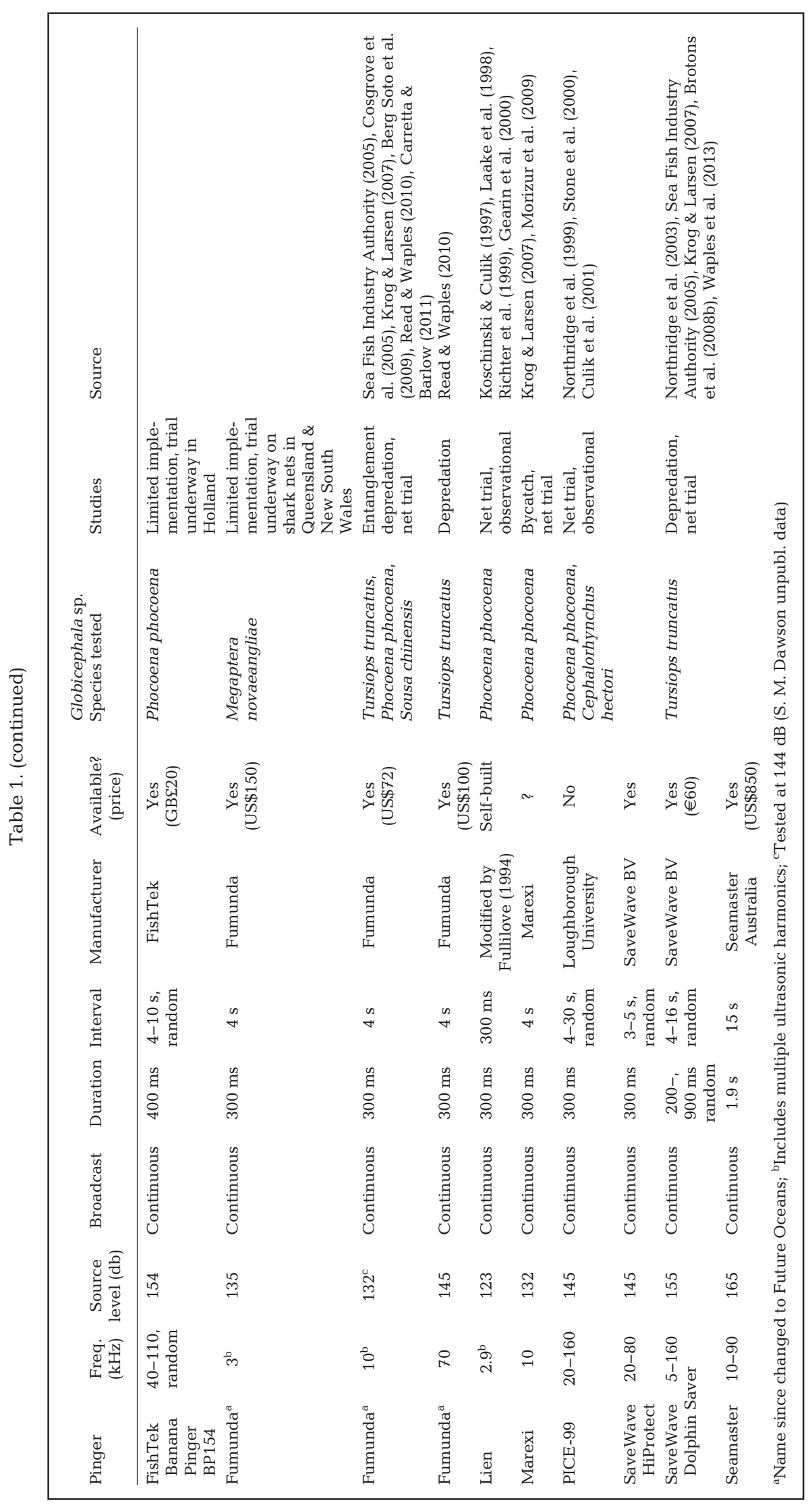


mercial gillnet fisheries, (2) studies of the behaviour of small cetaceans around pingers or gillnets, (3) observations of bycatch rates in fisheries in which pingers are used as part of a mitigation strategy, and (4) studies of the use of pingers to reduce depredation by dolphins. We include the latter because depredation can result in entanglement, and these studies provide insight into how dolphins react to pingers. We have reviewed both published and unpublished studies. For studies not published in peer-reviewed journals, we required that a report of professional quality was available detailing the study's methods and results. We attempt to summarise what we see as the emerging lessons and remaining uncertainties.

\section{CONTROLLED EXPERIMENTS IN GILLNET FISHERIES}

Researchers wishing to determine whether pingers will reduce bycatches of small cetaceans in a commercial gillnet fishery typically employ an experimental protocol in which bycatch rates are compared in nets with and without active pingers. Whenever possible, all other attributes of the nets (e.g. mesh size, length, depth, hanging ratio) are kept constant. Independent observers are used to monitor bycatch rates in both types of nets. Some experiments are quite elaborate, including blind protocols in which neither fishers nor observers know which pingers are active or silent, to eliminate any chance of intentional or unintentional bias. In such cases, the pingers are activated upon immersion in salt water (e.g. Kraus et al. 1997). After several studies had shown that harbour porpoise bycatch in gillnet fisheries can be substantially reduced by using pingers, several recent studies in European waters have used less rigorous experimental designs to test specific devices in particular fisheries. In these cases, the main objective has been to assess whether the devices are effective and practical under realistic fishery conditions rather than in a controlled experiment.

We reviewed 19 controlled experiments in which the effect of pingers on bycatch rates of dolphins or porpoises in gillnet fisheries was examined. Fourteen of these focussed on harbour porpoises (Table 2). Only 3 of these studies failed to produce statistically significant reductions. In 1 of these, no porpoises were caught in either control nets or nets with pingers (Carlström et al. 2002). In another, the pingers used had several faults which resulted in their failure (Northridge et al. 1999), while in the third study, sample sizes were small, and there was also a high rate of pinger failure (Morizur et al. 2009). Even if a bias exists, in which studies demonstrating significant differences are more likely to be submitted and accepted for publication than those that do not, this is a striking result. Taken together, they indicate that large reductions in harbour porpoise bycatch can be achieved in controlled experiments with a variety of pinger types over much of the species' range. We concur with the results of previous reviews (e.g. IWC 2000) that further experimentation to evaluate the efficacy of pingers with harbour porpoises and gillnet fisheries is unnecessary.

The other 5 controlled experiments addressed the bycatch of franciscana in Argentina (Bordino et al. 2002), a variety of small cetacean species off California (Barlow \& Cameron 2003) and off Peru (Alfaro Shigueto 2010), striped dolphins in the Mediterranean (Imbert et al. 2007), and bottlenose dolphins in Australia (McPherson et al. 2004). The first 3 studies used the Netmark 1000 pinger, the most extensively tested alarm, and produced bycatch reductions $>70 \%$. The acoustic specifications of this unit are now required for pingers used in the formal 'Take Reduction Plans' of the California driftnet fishery and the Gulf of Maine ground fish gillnet fishery, but the device itself is no longer sold commercially.

The trials using pingers to reduce bycatch of striped dolphins in the Thonaille fishery for tuna in the NW Mediterranean (Imbert et al. 2007) are difficult to interpret because an initial controlled experiment in August 2001 was followed by 2 seasons of simple observation of the effects of widespread, but inconsistent, pinger use with few control operations. Nevertheless, a total of 344 pingered and unpingered driftnet sets were monitored from 2001 to 2003. Two pinger types (Aquamark 200 and Fumunda $10 \mathrm{kHz}$ ) were trialled. The 2001 data showed a significant reduction $(81 \%)$ in striped dolphin bycatch with the use of Aquamark pingers, but subsequent bycatch rates with more widespread deployment were highly variable and not consistent with the low rates initially observed. At least 4 factors may have been involved: (1) skippers apparently used the devices sparingly; (2) devices were not always used at the correct spacing; (3) depleted batteries were not dealt with consistently (which required the purchase of new pingers in the case of the Aquamark device); and (4) at times nets correctly equipped with functioning pingers caught dolphins at a rate similar to nets without pingers, and some of these dolphins seem to have been fatally attracted to the devices rather than displaced. 


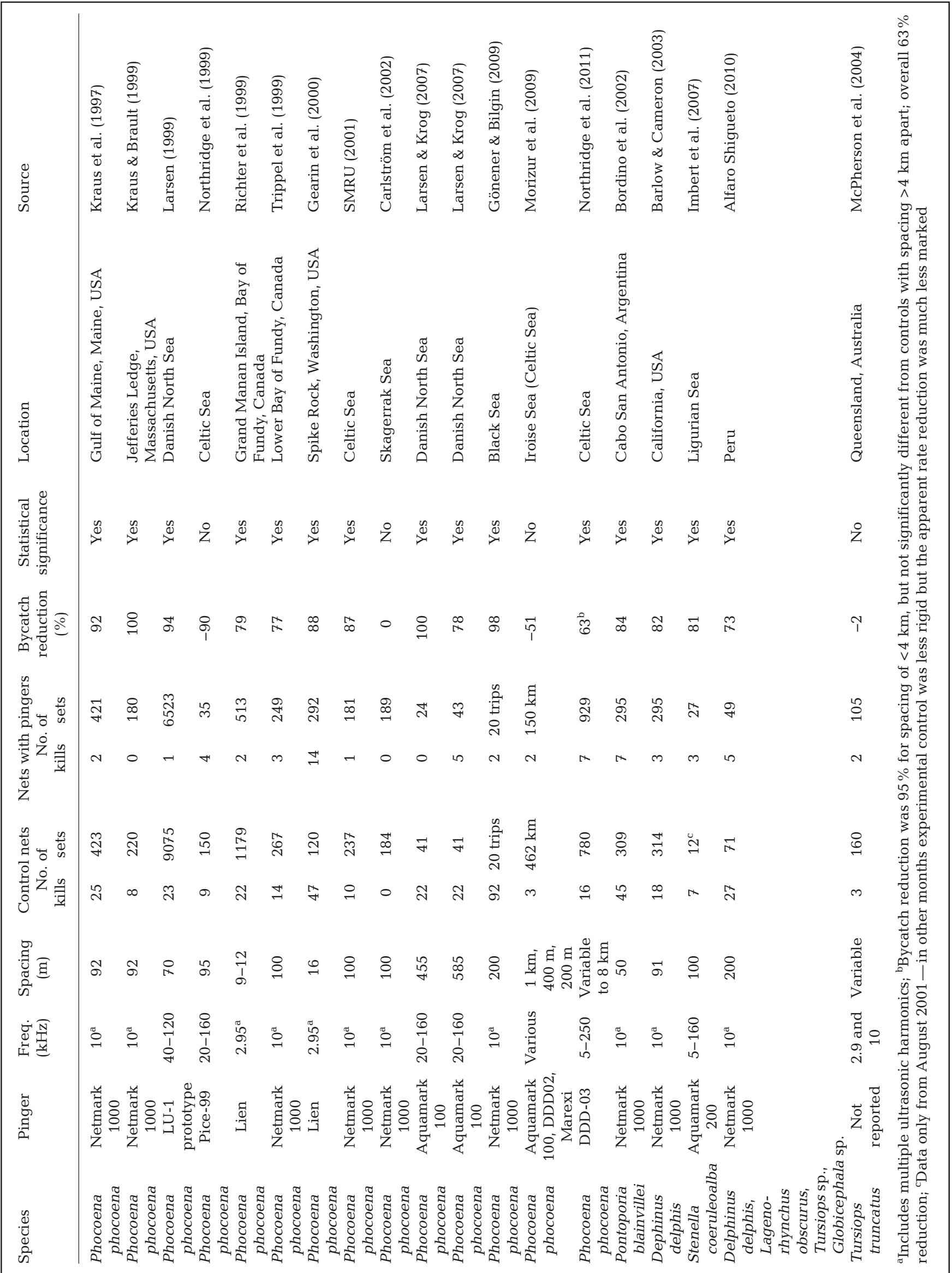


Too few dolphins were caught for McPherson et al.'s (2004) trials to be statistically powerful, but their results do not suggest that these pingers caused any reduction in the bycatch of bottlenose dolphins. Observers in this study also noted that bottlenose dolphins sometimes behaved aggressively toward the pingers, repeatedly attacking them.

\section{STUDIES OF BEHAVIOURAL RESPONSES TO PINGERS}

Controlled experiments on the effects of pingers on bycatch rate obviously provide the most direct test of their efficacy as a mitigation strategy, but studies of the behavioural response of animals to pingers can be extremely informative. Such an approach allows investigation of the mechanism of bycatch reduction, which is seldom shown by controlled experiments alone. Behavioural studies also have broad appeal because no animals are killed. In addition, such studies are typically much less expensive than the controlled experiments described above.

Researchers have used several approaches to examine the behavioural response of small cetaceans to pingers. In approximately half of the studies we reviewed, researchers used theodolites to track the movements of individuals or groups in the vicinity of a pinger or an actual or simulated gillnet (Table 3). The theodolite is used to estimate the position of individual animals or groups of animals at the surface. This allows researchers to compare closest approach distances when pingers are active and silent and, thus, to determine whether animals are displaced by the sound of the device. Unfortunately, several studies have considered each surfacing as an independent event, when in fact they are auto-correlated. This inflates sample size and can result in a falsely significant statistical test. The simplest way around this problem is to use only the closest observed approach distance for each group of dolphins or porpoises (Dawson \& Lusseau 2005).

In several studies researchers observed the response of animals to an active pinger lowered from a nearby boat. Six studies supplemented or replaced visual observations by monitoring the occurrence of echolocation signals using click detectors (e.g. Cox et al. 2001, Desportes et al. 2006, Leeney et al. 2007, Northridge et al. 2008, Carlström et al. 2009, Hardy \& Tregenza 2010). In about half of the studies we reviewed, the studies were conducted blind, so the observers did not know whether the pinger was active.
All but one study of harbour porpoises showed some degree of avoidance, fewer acoustic detections (Hardy \& Tregenza 2010), or physical displacement in which animals surfaced farther away when pingers were active, in some cases by several hundred metres. The remaining study (Desportes et al. 2006) showed no displacement reaction to Aquamark 100 pingers, despite demonstrated bycatch reductions using this pinger in controlled experiments (Larsen \& Krog 2007). The Desportes et al. (2006) study took place in an experimental area where pingers had been used in previous years.

The results of studies of other species are less clear. Common dolphins in Ireland showed no obvious reaction to a variety of pingers presented from a boat (Berrow et al. 2008), nor did individuals of this species react to several pinger signals deployed from a boat in Spain (Sagarminaga et al. 2006). Common dolphins in France, however, apparently showed a dramatic reaction to a DDD pinger (van Marlen 2007). Another study in England showed a decrease in click detections (presumed to be common dolphin) when a DDD-02 was deployed on a gillnet compared with when the net and pinger were absent (Northridge et al. 2008).

Surfacing positions of tucuxi Sotalia fluviatilis (Monteiro-Neto et al. 2004), Sousa chinensis (Berg Soto et al. 2009) and Hector's dolphin (Stone et al. 1997) were not obviously affected by the presence of active Netmark 100 or Fumunda pingers. These species did not show the clear zone of displacement demonstrated by harbour porpoises.

Bottlenose dolphins exhibit variable responses to pingers. Cox et al. (2004) observed fewer dolphin groups within $100 \mathrm{~m}$ of nets with active pingers compared to nets with inactive pingers, but there was no significant difference in closest observed approach. Leeney et al. (2007) monitored the echolocation activity of bottlenose dolphins in the vicinity of moored pingers using T-POD echolocation detectors. These researchers tested 2 Aquatec pinger types, one that continuously produced sound ('continuous' pinger, CP) and one that emitted sound only after detecting dolphin echolocation clicks ('responsive' pinger, RP), against dummy pingers that made no sound. The CP and RP pingers made broadband frequency-modulated (FM) sweeps with a source level of $165 \mathrm{~dB}$ - much louder than most other pingers used to reduce the bycatch of small cetaceans. There were significantly fewer dolphin echolocation detections when the CP was active. There was also less echolocation activity in the presence of active RPs, but the active versus dummy comparison was non- 


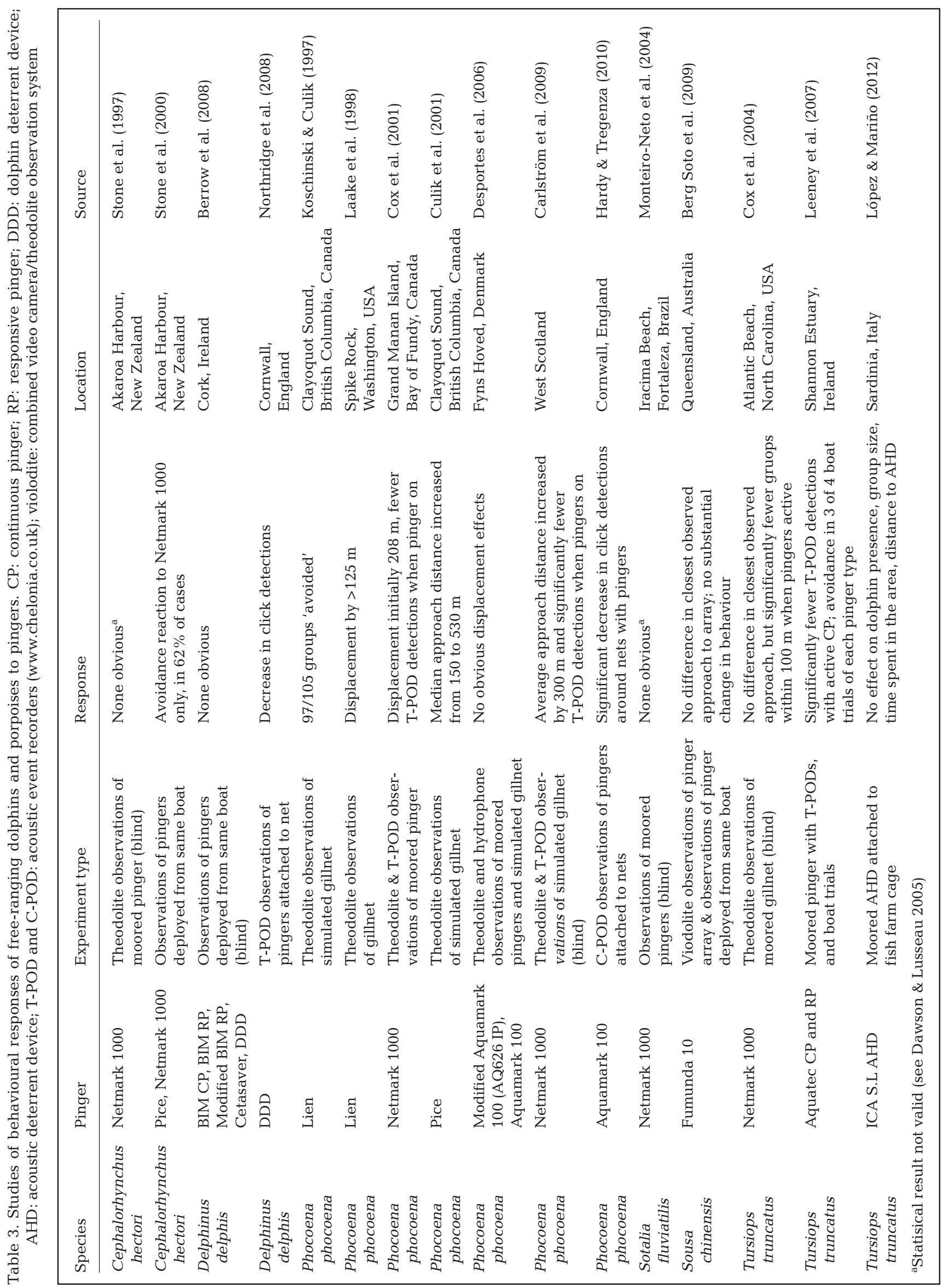


significant due to more variable reactions to the RP. It is possible that reduced acoustic detection was caused by a reduction in vocalisation rather than displacement (e.g. Cox et al. 2001). Both types of pingers were also used 4 times each in separate trials from a boat to observe visually the responses of the nearby bottlenose dolphins (Leeney et al. 2007). While the sample size is very small, and the trial conditions were somewhat artificial (see subsection 'Studies of behavioural responses to pingers'), strong avoidance reactions occurred in 3 of the 4 trials for each pinger.

\section{IMPLEMENTATION IN COMMERCIAL FISHERIES}

\section{Gulf of Maine bottom-set gillnet fishery}

Management of harbour porpoise bycatch in gillnet fisheries along the north-eastern United States is described in the 'Harbor Porpoise Take Reduction Plan' (www.nero.noaa.gov/protected/porptrp/). The plan, implemented in 1999, uses a mixture of approaches, including time-area restrictions on fishing effort, modifications to gear and a requirement to use pingers in certain times and areas. Under this plan, a pinger is defined as 'an acoustic deterrent device which, when immersed in water, broadcasts a $10 \mathrm{kHz}( \pm 2 \mathrm{kHz})$ sound at $132 \mathrm{~dB}( \pm 4 \mathrm{~dB})$ re 1 micropascal at $1 \mathrm{~m}$, lasting 300 milliseconds $( \pm 15$ milliseconds), and repeating every 4 seconds $( \pm 0.2$ seconds).' During routine monitoring of bycatch on commercial vessels, observers reported that gillnets equipped with a full complement of pingers (spaced no further than $92 \mathrm{~m}$ apart) caught $60 \%$ fewer porpoises per haul than nets without pingers (Palka et al. 2008). This reduction is much smaller than that achieved in the controlled experiment conducted in this same fishery (92\%; Kraus et al. 1997). Palka et al. argue that this could be because the current fishery uses a range of mesh sizes, while those used in the initial experiment have a higher bycatch rate. It is likely that other factors also contribute to this smaller reduction in bycatch rate (see 'Why are pingers less effective in real fisheries than in controlled experiments?').

The most interesting observation, however, is that nets equipped with some pingers, but not a full complement, catch $>2.5$ times as many porpoises than those with no pingers (Palka et al. 2008). Thus, partial implementation of this conservation strategy can be worse than no implementation at all. The most important impediment to the use of acoustic pingers to reduce bycatch in this fishery is a lack of compliance. As noted by Cox et al. (2007), during 2003, fishermen deployed gillnets without functioning pingers in 155 out of 173 trips monitored by on-board observers - a noncompliance rate of $78 \%$.

\section{California-Oregon drift net fishery}

A large-scale controlled experiment showed a significant reduction in the bycatch of marine mammals, particularly of common dolphins (Barlow \& Cameron 2003) in this fishery (Table 2). The use of pingers has been mandated since 1998 as part of the 'Pacific Offshore Cetaceans Take Reduction Plan' (www.nmfs. noaa.gov/pr/interactions/trt/poctrp.htm).

Since the implementation of pingers in this fishery, the entanglement rate of common dolphins has been reduced by approximately half (Carretta \& Barlow 2011), and bycatch of beaked whales has been eliminated (Carretta et al. 2008). Comparison of recent bycatch rates with those observed soon after adoption of pingers shows no evidence of habituation. Hence, in this fishery, like that in the Gulf of Maine, pingers have been effective in reducing cetacean bycatch, though not to the level seen in the preceding controlled experiments. Pinger failure is an important issue in this fishery too; sets with 1 or more failed pingers had a significantly higher bycatch rate of cetaceans than sets that were fully equipped with functional pingers (Carretta \& Barlow 2011).

On observed vessels, compliance with the requirement to use pingers has remained $>98 \%$ since they were made mandatory (Carretta \& Barlow 2011). An increasing fraction of the vessels in the CaliforniaOregon fishery (11 of 34 in 2009) are regarded as being too small to accommodate observers, so compliance and bycatch in this part of the fleet is unknown. Nevertheless, compliance regarding pinger use appears to be considerably better in this fishery than in the Gulf of Maine. Future research should examine why compliance is so different in these 2 fisheries.

In European waters, where EU legislation requires the use of pingers to minimise harbour porpoise bycatch in certain fisheries, several other studies have been conducted to test the robustness and practicality of pingers in fishing operations (Sea Fish Industry Authority 2003, 2005, Cosgrove et al. 2005, Le Berre 2005, Lunneryd 2006, Krog \& Larsen 2007). Most pinger types showed significant operational problems, including time taken in attachment, diffi- 
culty of checking functionality, propensity for tangling the gear and unreliability. For some pinger types failure rates exceeded $50 \%$ (e.g. Sea Fish Industry Authority 2003, Cosgrove et al. 2005). These issues are important impediments to widespread adoption of this mitigation approach, and were not all fully evident in prior scientifically controlled experiments.

\section{USE OF PINGERS TO REDUCE DEPREDATION}

Animals involved in depredation are, by definition, seeking to remove captured fish from a net, a process which can damage both catches and gear. The economic losses resulting from such interactions provide one of the primary incentives to use an acoustic device. The second incentive is provided by the risk of entanglement to the animals involved. An example showing both incentives is the inshore gillnet fishery for Spanish mackerel Scomberomorus maculatus which operates near Cape Hatteras on the east coast of the United States (Read et al. 2003, Waples et al. 2013).

It is striking that reported depredation of gillnets by cetaceans almost always involves bottlenose dolphins; many of these reports arise from the Mediterranean (Lauriano et al. 2004, 2009, López 2006, Brotons et al. 2008a, Rocklin et al. 2009). Several studies have addressed whether pingers reduce damage to gillnets and captured fish, testing a number of different pinger types (Table 4). Interpretation of these trials is complicated by the fact that both low-level (ca. $132 \mathrm{~dB}$ ) and high-level (>170 dB) devices have been used. Some of these studies have examined only a small number of sets and, hence, had low statistical power to detect effects (see Dawson et al. 1998, for discussion of power in this context). In addition to the studies reported here, there have been a number of uncontrolled and poorly documented 'experiments' with acoustic pingers in attempts to address depredation.

In general, experiments have demonstrated a small reduction in the damage to nets (reflected in the number of holes, for example) and increases in fish catches when acoustic pingers are employed (Northridge et al. 2003, Brotons et al. 2008b, Gazo et al. 2008, Buscaino et al. 2009). Several other issues limit our ability to draw broad conclusions from this work, including the existence of numerous other marine predators (sharks, turtles and other fishes) that engage in depredation, and the fact that some fish lost to depredation are removed completely, i.e. they cannot be counted. Observations of the behaviour of bottlenose dolphins around nets equipped with pingers (see Brotons et al. 2008b, Waples et al. 2013) suggest that the pingers can reduce the frequency with which dolphins interact with fishing gear, but do not eliminate such interactions.

In at least 2 cases, however, trials with pingers have not shown any reduction in bottlenose dolphin depredation of gillnets in the Mediterranean (Corsica, L. Rossi et al. unpubl. data; Cyprus, M. Hadjichristophorou unpubl. data). Neither study has been formally published, which underscores the problem that negative results are less likely to be published.

Importantly, although bycatch rates of bottlenose dolphins are typically very low in these gillnet fisheries (compared, for example, with those of harbour porpoises in the Gulf of Maine), there have been at least 2 incidences of lethal entanglements in nets equipped with active pingers.

Northridge et al. (2003) investigated the effect of SaveWave pingers on depredation of trammel nets in the eastern Mediterranean by observing 76 sets of strings with inactive pingers and 70 with active pingers, where strings were randomly allocated a pinger type. A bottlenose dolphin was found dead in 1 string equipped with active pingers. Its stomach contained undigested prey and a piece of $34 \mathrm{~mm}$ mesh from a trammel net, clear evidence of the risks of depredation to the animals concerned. A second dolphin was killed in trials of a prototype $70 \mathrm{kHz}$ $145 \mathrm{~dB}$ Fumunda pinger undertaken off Cape Hatteras, North Carolina, USA, in a gillnet fishery for Spanish mackerel (Read \& Waples 2010). This pinger was specifically designed to deter dolphins from approaching nets; its transmitting frequency was set at the maximum sensitivity of bottlenose dolphin hearing (Au 1993). Although isolated incidents, such reports do not inspire confidence that acoustic deterrents are a useful approach to minimizing bottlenose dolphin bycatch.

In summary, the studies of pinger effects on depredation by bottlenose dolphins show relatively small and variable reductions in net or catch damage. As noted above, there are issues of low statistical power in some studies (e.g. Gazo et al. 2008, Buscaino et al. 2009), but observed reductions are not consistently significant or of substantial economic benefit. Perhaps most telling is the fact that we are unaware of any case in which fishermen have voluntarily adopted and continued the use of acoustic pingers to reduce depredation, although it is certainly true that fishermen have experimented with such devices outside formal experimental settings. The number of entan- 


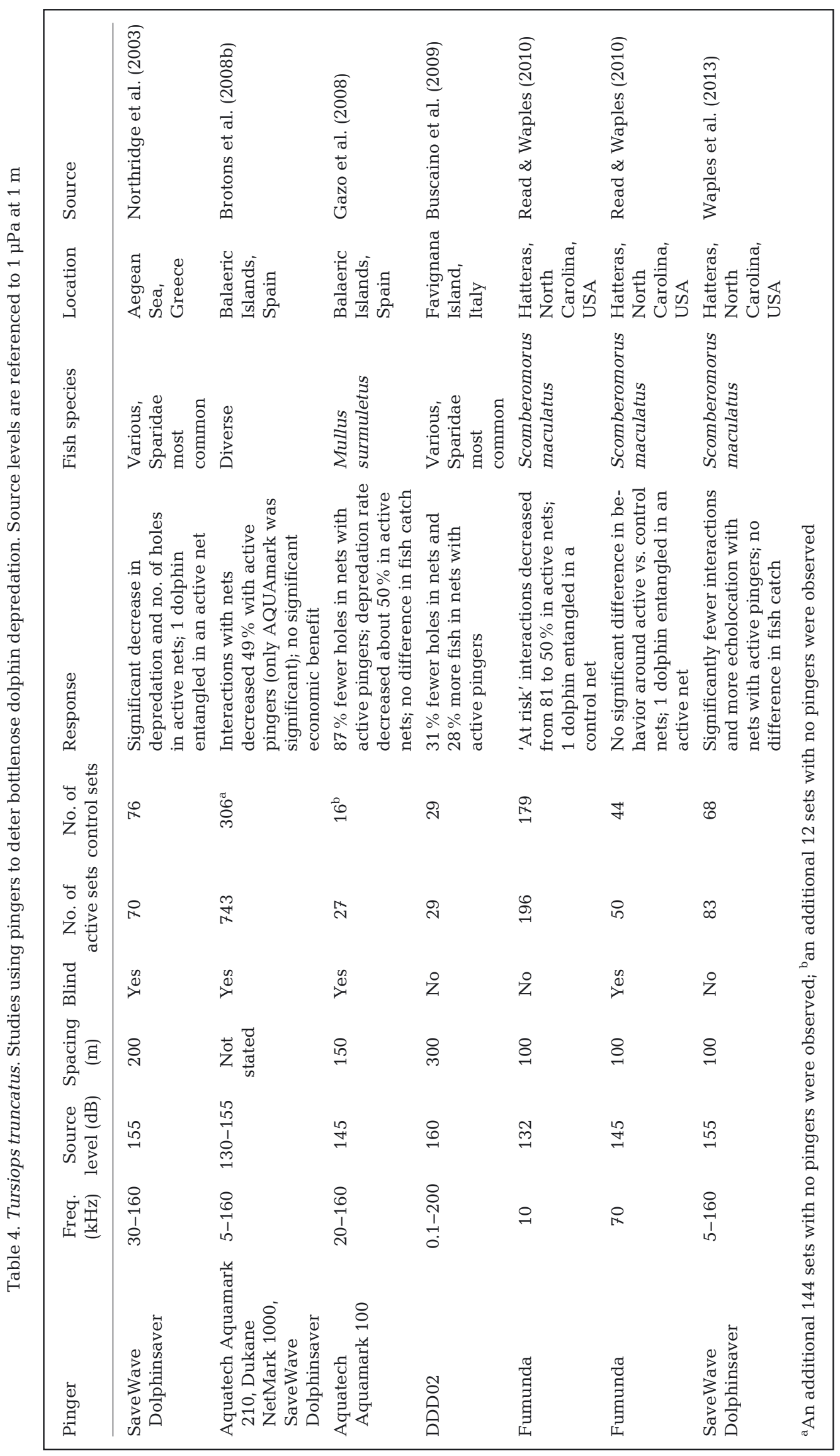


glements recorded in these experiments is too small to address quantitatively the question of whether pingers reduce the entanglement risk associated with depredation. Nevertheless, we know of 2 studies in which dolphins were fatally entangled in alarmed nets, illustrating that pingers do not eliminate entanglement risk. Thus, for the animals concerned, depredation is not a 'free lunch'. There is no evidence that pingers which are specifically designed to reduce depredation (and hence are louder) are any more effective in reducing entanglement than the quieter devices designed to reduce entanglement of porpoises.

Several authors have commented on the possibility that acoustic pingers could function as an unintentional dinner bell (e.g. Mate \& Harvey 1987, Dawson 1991, Kraus 1999). Most of these cautions clearly had pinnipeds in mind (Jefferson \& Curry 1996), but bottlenose dolphins involved in depredation could easily use pingers to enhance their ability to find nets (e.g. Read et al. 2003). The behavioural flexibility characteristic of this species facilitates opportunistic foraging. It seems to us that these animals are likely to tolerate even high-output pingers if there is a food 'reward'. We note also that high-output acoustic pingers do not produce sounds that are nearly as loud as bottlenose dolphins' own sounds (Au et al. 1974). We also note that there are several cases in which dolphins have been entangled close to active pingers and that there are also reports of aggressive behaviour by bottlenose dolphins towards pingers (see subsection 'Studies of behavioural responses to pingers').

\section{REMAINING QUESTIONS}

\section{Will habituation result in a decrease in the effectiveness of pingers?}

Habituation is usually thought of as a gradual lessening of behavioural response to a repeated stimulus and seems to be a general feature in the animal kingdom. Several authors have raised the question of whether habituation will cause reduced reaction to pingers over time and compromise effectiveness in reducing bycatch.

The most salient evidence for a lack of habituation comes from temporal trends of bycatch rates in the 2 longest running implementations of pingers in gillnet fisheries: the Gulf of Maine and California-Oregon. In neither case is there evidence of a long-term increase in bycatch rates (as would reflect a diminu- tion in their efficacy) when the recommended numbers of functioning pingers are used on each string of nets (Palka et al. 2008, Carretta \& Barlow 2011).

Interestingly, however, several observational studies of harbour porpoises have shown evidence of habituation in an experimental context. Cox et al. (2001) made theodolite observations of harbour porpoises in the vicinity of a moored Netmark 1000 pinger and noted that the initial mean displacement (208 $\mathrm{m}$ ) was reduced by half in $4 \mathrm{~d}$, and by $11 \mathrm{~d}$ was not significantly different from the control. Cox et al. also noted that echolocation rate and occurrence, measured with a T-POD acoustic event recorder, were significantly lower when the pinger was active than when it was silent. A broadly similar result was obtained by Carlström et al. (2009), who used a similar methodology but multiple T-PODs at different ranges from a simulated gillnet equipped with multiple Netmark 1000 pingers. Like Cox et al. they observed a clear initial displacement and lower echolocation rate with active pingers. Echolocation rate near pingers, however, increased over time at some locations, which was interpreted as evidence of habituation (Carlström et al. 2009). Following 2 seasons of trials of alarmed versus non-alarmed nets, all gillnets used in the 1997 trials by Gearin et al. (2000) were alarmed, in part to study habituation. No porpoises were taken in the first $18 \mathrm{~d}$ of the 1997 season, and 11 of the 12 porpoises taken were taken in the last $2 \mathrm{wk}$ of the fishery. While not conclusive, this suggests that habituation may have occurred, with the consequence of higher entanglement rate. Taken together, these studies suggest that some degree of habituation to the sounds of pingers could occur in inshore areas where porpoises are at least seasonally resident.

Habituation will only increase the risk of entanglement if the resulting displacement is less than half of the distance between adjacent pingers on the nets. Hence, reduction of displacement distance per se might not be a problem. The key issue is whether habituation results in approaches close enough to result in entanglement. Further research is required to tease apart the effect of pingers on the fine-scale behaviour of porpoises and other species around gillnets.

It seems likely that habituation would compromise the efficacy of acoustic pingers used to deter interactions such as depredation, in which animals gain a reward from ignoring the stimulus. Indeed, Northridge et al. (2003) showed a decline in effectiveness of the pingers in reducing bottlenose dolphin depredation as the trial continued into a second month. 


\section{Why are pingers less effective in real fisheries than in controlled experiments?}

In both cases in which pingers have been formally required as a mitigation strategy in commercial fisheries, the real-world reductions in bycatch rate have been considerably less than those achieved under experimental conditions. In the California-Oregon experiment common dolphin bycatch was reduced by $82 \%$ in driftnets with pingers versus control nets (Barlow \& Cameron 2003). In the New Hampshire gillnet experiment the corresponding reduction in bycatch rate of harbour porpoises was $92 \%$ (Kraus et al. 1997). After pinger use was mandated, entanglement rates of common dolphins dropped by about $50 \%$ in California-Oregon driftnets, while those of harbour porpoises in New England gillnets dropped by $60 \%$.

In both cases, several potentially confounding factors may have reduced apparent effectiveness. There have been shifts in the distribution of fishing effort in both fisheries, and other management measures (including time-area closures and gear modifications) have been implemented to address the catch of both target and non-target species. In addition, education and outreach programs have varied in their scope and efficacy.

The single largest confounding factor, however, seems to be compliance with the regulations. Compliance in the New England fishery has been highly variable, and, as noted above, at times remarkably poor. In New England the proportion of hauls using the required number of pingers fell from between 70 to $95 \%$ (depending on management area) in 1999 to 2000 to a low of 0 to $38 \%$ between 2003 and 2005. In 2007, after workshops explaining the need to use pingers, these proportions climbed to approximately 50 to $80 \%$ (C. D. Orphanides \& D. L. Palka unpubl. data). The lack of compliance with the requirement to use pingers in both fisheries (even when federal observers are aboard a fishing vessel) is a caution for fisheries in other areas.

It should be noted that there is a singular exception to the general observation that pingers are less effective in real fisheries than in controlled experiments. Since pingers have been adopted as part of the management strategy there have been no beaked whales taken in the California-Oregon driftnet fishery (Carretta et al. 2008). The likelihood of this having occurred by chance alone is vanishingly small.

\section{How do pingers work?}

Four main hypotheses have been proposed to explain how pingers could reduce the bycatch rates of small cetaceans (e.g. Dawson 1994, Kraus 1999, IWC 2000):

(1) The sounds of acoustic pingers are generally aversive and act to displace animals from the vicinity of the pinger.

(2) Pinger sounds encourage echolocation or otherwise alert the animals to the presence of the net and hence make avoidance of entanglement more likely.

(3) Pinger sounds interfere with the animals' sonar, causing them to leave the area.

(4) Pinger sounds act by altering the distribution of prey.

Of these, only the 'aversive' hypothesis (1) has strong support and only for 1 species, the harbour porpoise. As described above, studies using theodolites to record surfacing positions of harbour porpoises have generally shown a clear zone of displacement around active pingers (e.g. Gearin et al. 2000, Culik et al. 2001; for an exception see Desportes et al. 2006). Such displacement zones do not appear to occur with bottlenose dolphins; indeed Cox et al. (2004) found no significant difference in the closest point of approach of dolphins to active or inactive pingers. No clear zone of exclusion was observed in studies of Hector's dolphin (Stone et al. 1997) or of tucuxi (Monteiro-Neto et al. 2004). Pseudo-replication problems in both these studies invalidate their apparently significant statistical results (Dawson \& Lusseau 2005).

The 'alerting' hypothesis (2) has also been studied in harbour porpoise and bottlenose dolphins. Studies of reactions to moored pingers, combining visual observations with T-POD acoustic detections of echolocation, have shown that both species usually echolocate less frequently in the vicinity of an active pinger than near an inactive one (Cox et al. 2001, Leeney et al. 2007, Carlström et al. 2009, for exception see Desportes et al. 2006). Further, if pingers work by stimulating echolocation and hence increasing the chance of net detection, one would expect avoidance only at ranges of $10 \mathrm{~s}$ of metres, consistent with studies of the detection ranges of gillnets by captive dolphins and porpoises (Kastelein et al. 2000). Yet when pingers are avoided by harbour porpoises, the displacement ranges are typically on the order of 100s of metres (Anderson et al. 2001, see our Table 3). This implies that the pinger sounds themselves are aversive.

We are not aware of any published studies specifically addressing Hypothesis 3, whether pingers function by 'jamming' echolocation or making it less effective. Most current pingers mimic the acoustic 
output of the discontinued Dukane Netmark 1000 which proved effective at reducing bycatch in several experiments (Table 2). These pingers emit a $10 \mathrm{kHz}$ tone every $4 \mathrm{~s}$ that is relatively rich in harmonics, but there is very little energy near $130 \mathrm{kHz}$, the dominant frequency of harbour porpoise echolocation signals $(\mathrm{Au}$ et al. 1999). Thus, it seems unlikely that these pingers act by making echolocation more difficult. We note, however, that some pingers marketed to reduce depredation are at least intended to work by jamming echolocation (e.g. SaveWave 'high-protect dolphin saver').

Hypothesis 4 was raised by Kraus et al. (1997), who noted significantly lower catch rates of Atlantic herring Clupea harengus, a primary prey species of harbour porpoises, in the New Hampshire experiment. Thus, these authors reasoned, the lower porpoise catch could have been due to indirect effects on their prey. A springtime test of the same pingers in the same fishery confirmed the effectiveness of pingers in reducing porpoise bycatch, but did not show significant effects on fish catches (catches in control and experimental nets differed by $<10 \%$; Kraus \& Brault 1999). Likewise, Trippel et al. (1999) found no differences in catches of harbour porpoise prey in nets with and without Dukane pingers. Tests of 3 different pinger types (Lien, Dukane and PICE) in a commercial herring fishery showed that the Lien pinger $(2.9 \mathrm{kHz})$ was associated with a significantly higher catch rate of herring, but that nets with the other 2 pingers had very similar catch rates to nets without pingers (Culik et al. 2001). These studies, in combination with Wilson \& Dill's (2002) finding that a Dukane pinger had no observable effect on the behaviour of adult herring, indicate that effects on prey species are not responsible for the observed effects of pingers on porpoises.

It is clear that the aversive hypothesis best explains the effects on harbour porpoises, but pingers in gillnets have also significantly reduced catch rates of common dolphins (Barlow \& Cameron 2003), beaked whales (Carretta et al. 2008), franciscana (Bordino et al. 2002) and, at least temporarily, striped dolphins (Imbert et al. 2007). It is possible that the aversive hypothesis might also explain these results, but at present there is no evidence to support or refute this hypothesis.

\section{Under what circumstances will pingers be effective?}

This question has 2 components - for which species and in which fisheries will pingers be effective? Pingers have been tested in the field on harbour porpoises, franciscana, common dolphins, beaked whales, Hector's dolphins, tucuxi, striped dolphins, and bottlenose dolphins (see Tables 2, 3 \& 4). Four species (harbour porpoises, franciscana, striped and common dolphins, and 1 species group (beaked whales) have shown unequivocal reductions in bycatch and/or clear avoidance of pinger sounds (Kraus et al. 1997, Bordino et al. 2002, Barlow \& Cameron 2003, Carretta et al. 2008).

For other species, the evidence is somewhat contradictory. With bottlenose dolphins, Cox et al. (2004) and Waples et al. (2013) found that 2 types of pingers both resulted in fewer animals approaching within $100 \mathrm{~m}$ of the net. Some studies have shown at least temporary reduction in net damage by bottlenose dolphins when pingers are used (Brotons et al. 2008b, Gazo et al. 2008). Other studies suggest no reduction in depredation (L. Rossi et al. unpubl. data) or a diminution of the effect over several weeks (Northridge et al. 2003). Entanglements in pingered nets in relatively small-scale trials (Northridge et al. 2003, McPherson et al. 2004, Read \& Waples 2010) suggest that pingers are not effective in reducing entanglement risk for this species. The apparently aggressive response of bottlenose dolphins to some pingers is disconcerting (McPherson et al. 2004).

There is no evidence that Hector's dolphins are physically displaced from moored Netmark 1000 pingers (Stone et al. 1997, Dawson \& Lusseau 2005). However, avoidance reactions were observed in 21 of 32 nearby dolphin groups when this pinger was immersed from a drifting boat (Stone et al. 2000). Boat-based trials have the advantage of allowing close observation, but they have important disadvantages, including the possibly confounding effect of the boat, and the potential for dolphins to be 'startled' (sensu Teilmann et al. 2006) by the sudden onset of pinger sounds at close range. Furthermore, they do not mimic the behavioural context associated with actively fishing nets. Thus, boat-based trials may provide poor measures of responses to pingers. Even if taken at face value, however, the reactions of Hector's dolphins were clearly less extreme than those of harbour porpoises, which are typically displaced some 100s of metres from functioning pingers. Acoustic pingers were used by some gillnet fishers in Canterbury, New Zealand, under a voluntary 'Code of Practice' (SE Finfish Management Company unpubl. data), but low levels of observer coverage made it impossible to determine whether this reduced entanglement rates. Additionally, compliance with the code of practice has been low in this fishery (Dawson \& Slooten 2005). 
We conclude that it is unreasonable to expect pingers to work with all small cetaceans. For harbour porpoises, at least, pingers work by displacing animals away from the net, so we recommend that a well-designed observational study of the behavioural reactions to pingers be conducted, in as realistic a situation as feasible (e.g. Cox et al. 2001), before employing pingers in full-scale field trials with any novel species.

Can we predict which species pingers might work for? Experience suggests that pingers are most likely to be successful in reducing bycatch of species which are generally neophobic or easily startled, such as harbour porpoises. In addition, low levels of philopatry (e.g. Read \& Westgate 1997) might reduce encounter rates with static fishing gear and hence delay habituation, should it occur. On this basis, generally we might expect phocoenid species to be more appropriate targets for bycatch reduction via pingers than coastal delphinids. The elimination (to date) of beaked whale bycatch in pinger-equipped Californian driftnets suggests a very high effectiveness for this group, which is also wary of vessels and has an oceanic distribution. Delphinids, particularly those showing very flexible behaviour, coastal distribution and high site fidelity, such as bottlenose dolphins, would seem among the least appropriate candidate species.

In some cases it may be impractical, or even unethical, to attempt to demonstrate the effectiveness of pingers in reducing bycatch. This may be because bycatch rates are very low, resulting in a requirement for extremely large (and costly) sample sizes (Dawson et al. 1998), or because the mortality of even a few individuals in a controlled experimental trial is unwarranted or unacceptable (see Read 2010). The latter situation is certainly true with Critically Endangered species, such as the vaquita or Maui's dolphin. Statistical power curves given by Dawson et al. (1998) provide some guidance on the sample sizes needed to demonstrate a target level of reduction, given knowledge of the entanglement rate in nets without pingers. Thus, efficacy will be very difficult (or impossible) to demonstrate for some species, no matter how susceptible those species are to pinger sounds.

In addition, pingers are likely to be employed effectively only under a certain set of socio-economic conditions. Many small-scale fisheries in the developing world are unlikely to have the economic resources to employ this mitigation approach. Even with an initial subsidy to purchase pingers and train fishery participants, it is unlikely that the devices will be maintained and used effectively long-term. And, as described in 'Implementation in commercial fisheries', partial ensonification of gillnets may be worse than not using pingers at all. Further, implementation of pingers is not straightforward, even in valuable fisheries in developed nations. A number of European trials have demonstrated problems with the durability and functionality of several of the available pinger models, and the difficulty of integrating them into mechanized hauling and setting. Fewer operational issues appear to be encountered with smaller coastal vessels fishing a smaller number of nets (Sea Fish Industry Authority 2005, Lunneryd 2006).

In more affluent countries with consumer-focused fish marketing, the development of accreditation schemes that purport to ensure sustainable production methods and management procedures could provide a means of ensuring higher levels of compliance with measures to minimize cetacean bycatch.

A wide variety of pingers has been produced (Table 1). Most use constant-frequency (CF) tones (with multiple harmonics). Several are modelled on the acoustic output of the Dukane Netmark 1000 $(10 \mathrm{kHz}, \mathrm{ca} .132 \mathrm{~dB}$ pulses lasting $300 \mathrm{~ms}$ repeating every 4 s). Several (e.g. Aquamark 200) use FM sweeps extending from audio to ultrasonic frequencies. Some broadcast randomized signals (e.g. Fishtek BP154) or signals at randomized intervals (e.g. SaveWave Dolphin Saver), in an attempt to minimize the chance of habituation. CF pingers have been tested in controlled experiments more often than any other type. At least 12 trials have shown significant reductions in bycatch due to their use (Table 2). FM pingers have been associated with bycatch reductions in 3 trials (Table 2). It is not clear whether randomizing the broadcast signal is more or less effective.

Quality control in pinger manufacture needs to improve. In addition to the reliability issues addressed earlier, there can be substantial variation in sound pressure level among pingers of the same brand and model. For example, 26 identical pingers, made by a leading manufacturer, and tested in August 2009 before first use, varied from 139 to $156 \mathrm{~dB}$ (re $1 \mu \mathrm{Pa}$ at $1 \mathrm{~m}$; Dawson \& Nowacek unpubl. data). The claimed sound pressure level (SPL) of these pingers was 147.5 dB. Likewise, Kraus et al. (1995) tested a random sample of 25 Dukane pingers, finding that SPL at the stated dominant frequency of $10 \mathrm{kHz}$ varied from 105 to $139 \mathrm{~dB}$. An independent accreditation system might improve confidence in pinger quality. 


\section{Could pingers exclude animals from important habitat?}

If pingers are effective, will marine mammals be displaced into less favourable habitat? Studies of harbour porpoises in areas where high-intensity AHDs are deployed have shown that this species can be displaced considerable distances by high levels of sound (Johnston 2002, Olesiuk et al. 2002). Also, the very clear exclusion zone shown for this species in most studies of pingers (e.g. Gearin et al. 2000, Culik et al. 2001, Carlström et al. 2009) shows that much lower sound levels can create a similar effect on a smaller scale. If this effect was permanent and if gillnets were set in preferred habitats, this could deny animals access to important habitat, especially if the animals have small home ranges. Indeed, deliberate exclusion from an entire bay has been proposed by the installation of a string of pingers across the ca. $17 \mathrm{~km}$ wide entrance of Puck Bay, in Poland, to mitigate bycatches of harbour porpoises in the bay, which has high levels of gillnet effort (ICES 2010). The success of this approach is as yet unknown.

At larger scales, however, displacement seems unlikely to be problematic. For example, Larsen \& Hansen (2000) estimated that pinger signals from the entire Danish gillnet fleet could potentially ensonify $<1 \%$ of the porpoises' habitat. Similarly, Northridge et al. (2011) showed that if the EU regulation on pinger use was fully implemented in SW England, $<1 \%$ of habitat would be lost if DDD-03 devices were used and exclusion was assumed to be complete to within a $2 \mathrm{~km}$ radius of each device. Given the large ranges of individual porpoises in these waters (e.g. Sveegaard et al. 2011) and the variety of habitats available, it seems unlikely that exclusion from important habitat will be a serious problem at a population level. Of greater concern would be the implementation of acoustic pingers to reduce bycatch of a neophobic species with very restricted ranges, particularly if nets were set repeatedly in important habitat.

\section{How many pingers are needed?}

Acoustic pingers are expensive, particularly when many nets are fished. In addition, they can hinder hauling and setting of nets. There is, therefore, considerable interest among fishers in reducing the number of pingers to the minimum required to maintain their effect (we note also that this may reduce the amount of sound unnecessarily broadcast into the ocean, unless fewer but much louder devices are used). Several pinger types produce signals louder than the $132 \mathrm{~dB}$ 'standard' (Table 1) to increase the distances over which they may be effective.

Carlström et al. (2009) found that the mean effective range of displacement of harbour porpoises by $10 \mathrm{kHz}$ Dukane pingers was $752 \mathrm{~m}$. This is much greater than the pinger spacing used in most experiments (e.g. Kraus et al. 1997) and considerably greater than the distance required under current regulations in the Gulf of Maine (92 m). Likewise, Larsen \& Krog (2007) found that increasing spacing between Aquamark 100 pingers to $455 \mathrm{~m}$ and even to $585 \mathrm{~m}$ produced bycatch reductions of similar magnitude to those found in other studies with less spacing between pingers.

These observations appear to conflict with the results of large-scale operational pinger use in the Gulf of Maine (see 'Gulf of Maine bottom-set gillnet fishery'), which show that reliable bycatch reduction occurs only if the usual (ca. $92 \mathrm{~m}$ ) spacing between pingers is used. If fewer pingers are used than required, or if some pingers are not effective due to failure, entanglement rates increase. It is possible that when the animal can hear multiple pingers at irregularly spaced intervals, it interprets a large gap between functioning pingers as a potential escape route (IWC 2000, Palka et al. 2008).

We believe that this apparent conflict points to the need for further quantitative evaluation of the effect of incomplete ensonification of gillnets under operational conditions. Such an evaluation should include: measurements of received levels along and around gillnets equipped with full and partial numbers of pingers, an assessment of the behavioural response of porpoises to such sound fields, and a rigorous examination of the effect of partial pinger coverage using bycatch data collected by observer programs. We note that the sound field generated by pingers will vary across locations (Shapiro et al. 2009), and behavioural responses will not be uniform.

\section{LESSONS FROM THE LAST DECADE}

We draw the following conclusions from the past decade of implementation, experimentation and observation.

(1) Pingers have been shown to be effective in reducing bycatch of harbour porpoises, beaked whales, common dolphins and franciscana. Their use does not appear to reduce the bycatch of bottlenose dolphins, nor is there strong evidence 
that they are effective in deterring depredation by this species. At the present time, we do not have enough information to assess their efficacy with other species.

(2) Effective implementation of pingers in gillnet fisheries is difficult and compliance is likely to be variable, even in relatively sophisticated fisheries in developed countries. Education, outreach and enforcement are all critical components of effective implementation plans. Based on past experiences, voluntary compliance will be the exception, rather than the rule, but may be fostered when included as part of a certification scheme. Post-implementation monitoring is critical to assess temporal trends in compliance and efficacy.

(3) Consistency of use and pinger durability are very important. Bycatch rates appear to increase when nets are only partially ensonified due to equipment failure or the use of fewer pingers than recommended (Palka et al. 2008, Carretta \& Barlow 2011). Thus, seemingly minor lapses in compliance and pinger reliability may result in higher bycatch rates.

(4) In the 2 longest-running programs that employ pingers, other mitigation approaches, such as time-area closures and gear modification, are also employed. Schemes which rely entirely on pingers, such as those enacted in Europe, are of unknown effectiveness.

(5) Pingers are unlikely to be adopted and/or used appropriately unless their use is mandated. Where pingers have been shown to be effective but their use is not mandated by regulation (such as in the Bay of Fundy, Canada - see Trippel et al. 1999), the devices are not used by fishermen. In Canterbury, New Zealand, they have been used voluntarily, but only $28 \%$ of observed sets showed compliance with deployment instructions (Dawson \& Slooten 2005).

(6) In programs implementing pinger use, ensuring compliance and ongoing effectiveness are both difficult and expensive. In some cases the cost of the monitoring required to demonstrate ongoing effectiveness may exceed the value of the fishery. To date, the costs of most monitoring programs have been borne by government support - effectively a subsidy of fishing operations. One notable exception is the New Zealand Conservation Services Programme, which is administered by the Department of Conservation and levies fishers for funds to support quantification and mitigation of their impacts (West et al. 1999).
(7) The requirement of a 'hard' target for bycatch reduction (e.g. total allowable bycatch) is critical (i.e. not just reduction per se, but reduction to $x$ ) for determining how pingers should be employed and how they should be integrated with other management approaches. Without a quantitative goal, it is impossible to assess efficacy. Setting a target for bycatch reduction also has a strong scientific benefit, as it facilitates using power analyses to design experiments that can detect meaningful effects with appropriate statistical power (Dawson et al. 1998).

(8) Pinger reliability has improved, but failure rates remain significant with some models. Several fishery trials have been conducted to examine practicality and reliability issues associated with using pingers (e.g. Sea Fish Industry Authority 2003, 2005, Cosgrove et al. 2005, Lunneryd 2006, Krog \& Larsen 2007). Failure rates around $50 \%$ or higher were reported for Aquamark and Savewave pingers in short-term trials by Cosgrove et al. (2005). Failure rates are also significant in fisheries with mandatory pinger use. In the Gulf of Maine bottom gillnet fishery, $64 \%$ of pingers in use in 2003 were not working when tested; in 2006/2007 this improved to 13\% (Palka et al. 2008). In the California-Oregon driftnet fishery, nets sampled for failed pingers showed a failure rate of about $18 \%$ (Carretta \& Barlow 2011). High failure rates and the difficulty of practical implementation are important impediments to pinger adoption in many fisheries.

\section{NOTE ADDED IN PROOF}

Recent analyses of data from the New England gillnet fishery show that compliance with the requirement to use pingers continues to be very poor. Despite considerable pressure to improve compliance (including the threat of large time-area closures if by-catch targets were exceeded), data from independent observers show that only $62 \%$ of sets in 2010-2012 had a full complement of functioning pingers on each string of nets (Orphanides 2012). Harbour porpoise bycatch levels in the Gulf of Maine have exceeded the Potential Biological Removal level in 6 of the past $7 \mathrm{yr}$, and bycatch rates were almost twice the target level in 2010 to 2012 (Orphanides 2012), reflecting a fundamental failure of fishermen to comply with these regulations. New England fishers were involved in the development of the pinger program and there is clear evidence that 
pingers can reduce bycatch in this fishery to sustainable levels when they are used appropriately (Palka et al. 2008), but systematic non-compliance has now lasted for more than a decade. Continued lack of compliance has led scientists on the Take Reduction Team to conclude that it is time to look for alternative mitigation strategies in New England. In addition, we suggest that it would be useful to understand why compliance is so poor in this fishery compared with that in the California-Oregon drift net fishery. Such information could help design future efforts to use pingers as a mitigation strategy in other gillnet fisheries.

Acknowledgements. The bulk of this paper was written while S.M.D. was on sabbatical at Duke University, the Lighthouse Field station (University of Aberdeen), and the Sea Mammal Research Unit (University of St Andrews). We are grateful to those agencies, and to Otago University, for their support. For conversations about pingers, and for sending us their papers we are also grateful to Jim Carretta, Jay Barlow, Liz Slooten, Debi Palka, Scott Kraus, Chris Orphanides, Ed Trippel, Geoff McPherson, Ron Kastelein and Tara Cox. We also thank the many fishermen in Europe and North America who have worked with us to test these devices in their fisheries.

\section{LITERATURE CITED}

Alfaro Shigueto J (2010) Experimental trial of acoustic alarms to reduce small cetacean bycatch by gillnets in Peru. Available at www.ruffordsmallgrants.org/rsg/ projects/joanna_alfaro_shigueto_0 (accessed 15 Dec 2012)

Anderson RC, Barlow J, Bowles AE (2001) Pingers are acoustic harassment devices. Working paper AND/INFO 3 presented to 'Mitigation of interactions between dolphins and fisheries through the use of acoustic harassment devices: effectiveness, impact and possible alternatives' workshop. ICRAM, Rome

Au WWL (1993) The sonar of dolphins. Springer, Heidelberg > Au WWL, Floyd RW, Penner RH, Murchison AE (1974) Measurement of echolocation signals of the Atlantic bottlenose dolphin, Tursiops truncatus Montagu, in open waters. J Acoust Soc Am 56:1280-1290

Au WWL, Kastelein R, Rippe T, Schooneman N (1999) Transmission beam pattern and echolocation signals of a harbor porpoise (Phocoena phocoena). J Acoust Soc Am 106: 3699-3705

Barlow J, Cameron GA (2003) Field experiments show that acoustic pingers reduce marine mammal bycatch in the California drift gillnet fishery. Mar Mamm Sci 19: 265-283

Berg Soto A, Marsh H, Everyingham Y, Parra G, Noad M (2009) The acoustic and surface behaviour of coastal dolphins in Queensland: implications for management. In: Marsh H (ed) Marine and tropical sciences researchfacility milestone report. Available at www.helenemarsh. com/publications/Unpublished/MarshMTSRF_FinalReport 300609.pdf (accessed 16 Dec 2012)
Berggren P, Wade PR, Carlström J, Read AJ (2002) Potential limits to anthropogenic mortality for harbour porpoises in the Baltic region. Biol Conserv 103:313-322

Berrow S, Cosgrove R, Leeney RH, Obrien J, Mcgrath D, Dalgard J, Gall YL (2008) Effect of acoustic deterrents on the behaviour of common dolphins (Delphinus delphis). J Cetacean Res Manag 10:227-233

Bordino P, Albareda D, Palmerio A, Mendez M, Botta S (2002) Reducing incidental mortality of franciscana dolphin Pontoporia blainvillei with acoustic warning devices attached to fishing nets. Mar Mamm Sci 18: 833-842

Bordino P, Kraus S, Alibareda D, Baldwin K (2004) Acoustic devices help to reduce incidental mortality of the Franciscana dolphin (Pontoporia blainvillei) in coastal gillnets. IWC SC/56/Sm12: 1-10. International Whaling Commission, Cambridge

> Brotons JM, Grau AM, Rendell L (2008a) Estimating the impact of interactions between bottlenose dolphins and artisanal fisheries around the Balearic Islands. Mar Mamm Sci 24:112-127

> Brotons JM, Munilla Z, Grau AM, Rendell L (2008b) Do pingers reduce interactions between bottlenose dolphins and nets around the Balearic Islands? Endang Species Res 5:301-308

Brownell RL Jr, Ralls K, Perrin WF (1989) The plight of the 'forgotten' whales: it's mainly the small cetaceans that are now in peril. Oceanus 32:5-11

Buscaino G, Buffa G, Sarà G, Bellante A and others (2009) Pinger affects fish catch efficiency and damage to bottom gillnets related to bottlenose dolphins. Fish Sci 75: 537-544

> Carlström J, Berggren P, Dinnetz F, Borjesson P (2002) A field experiment using acoustic alarms (pingers) to reduce harbour porpoise bycatch in bottom-set gillnets. ICES J Mar Sci 59:816-824

> Carlström J, Berggren P, Tregenza NJC (2009) Spatial and temporal impact of pingers on porpoises. Can J Fish Aquat Sci 66:72-82

Carretta JV, Barlow J (2011) Long-term effectiveness, failure rates, and 'dinner bell' properties of acoustic pingers in a gillnet fishery. Mar Technol Soc J 45:7-19

Carretta JV, Barlow J, Enriquez L (2008) Acoustic pingers eliminate beaked whale bycatch in a gillnet fishery. Mar Mamm Sci 24:956-961

Cosgrove R, Browne D, Robson S (2005) Assessment of acoustic deterrent devices in Irish gillnet and tangle net fisheries. Marine Technical Report: Project 05MT07, Bord Iascaigh Mhara (IBM), Irish Sea Fisheries Board, Dublin

Cox TM, Read AJ, Solow A, Tregenza NC (2001) Will harbour porpoises (Phocoena phocoena) habituate to pingers? J Cetacean Res Manag 3:81-86

Cox TM, Read AJ, Swanner D, Urian K, Waples D (2004) Behavioral responses of bottlenose dolphins, Tursiops truncatus, to gillnets and acoustic alarms. Biol Conserv 115:203-212

> Cox TM, Lewison R, Žydelis R, Crowder LB, Safina C, Read AJ (2007) Comparing effectiveness of experimental and implemented bycatch reduction measures: the ideal and the real. Conserv Biol 21:1155-1164

Culik BM, Koscinski S, Tregenza N, Ellis GM (2001) Reactions of harbor porpoises Phocoena phocoena and herring Clupea harengus to acoustic alarms. Mar Ecol Prog Ser 211:255-260 
Dawson SM (1991) Modifying gillnets to reduce entanglement of cetaceans. Mar Mamm Sci 7:274-282

Dawson SM (1994) The potential for reducing entanglement of dolphins and porpoises with acoustic modifications to gillnets. Rep Int Whal Comm 15(Spec Issue):573-578

Dawson SM, Lusseau D (2005) Pseudoreplication problems in studies of dolphin and porpoise reactions to pingers. Mar Mamm Sci 21:175-176

> Dawson SM, Slooten E (1993) Conservation of Hector's dolphins: the case and process which led to establishment of the Banks Peninsula Marine Mammal Sanctuary. Aquat Conserv 3:207-221

Dawson SM, Slooten E (2005) Management of gillnet bycatch of cetaceans in New Zealand. J Cetacean Res Manag 7:59-64

Dawson SM, Read AJ, Slooten E (1998) Pingers, porpoises and power: uncertainties with using pingers to reduce bycatch of small cetaceans. Biol Conserv 84:141-146

Desportes G, Amundin M, Larsen F, Bjørge A, Poulsen LR, Stenback J, Petersen N (2006) NIPPER: nordic interactive pinger for porpoise entanglement reduction. Final report to Nordic Council of Ministers Fjord \& Bælt, Kerteminde. www.kolmarden.com/PageFiles/1233/NIPPER\%20final \%20report.pdf

Fish JF, Vania JS (1971) Killer whale, Orcinus orca, sounds repel white whales, Delphinapterus leucas. Fish Bull 69: 531-535

Fullilove J (1994) How to make a gillnet 'pinger.' Natl Fisherman 75(1):29-30

Gazo M, Gonzalvo J, Aguilar A (2008) Pingers as deterrents of bottlenose dolphins interacting with trammel nets. Fish Res 92:70-75

Gearin PJ, Gosho ME, Laake JL, Cooke L, DeLong RL, Hughes KM (2000) Experimental testing of acoustic alarms (pingers) to reduce bycatch of harbour porpoise, Phocoena phocoena, in the state of Washington. J Cetacean Res Manag 2:1-9

Gönener S, Bilgin S (2009) The effect of pingers on harbour porpoise, Phocoena phocoena, bycatch and fishing effort in the turbot gill net fishery in the Turkish Black Sea coast. Turk J Fish Aquat Sci 157:151-157

Hardy T, Tregenza N (2010) Can acoustic deterrent devices reduce bycatch in the Cornish inshore gillnet fishery? Field studies. Cornwall Wildlife Trust, Truro

Hembree D, Harwood MB (1987) Pelagic gillnet modification trials in northern Australian seas. Rep Int Whal Comm 37:369-373

ICES (International Council for the Exploration of the Sea) (2010) Report of the study group for bycatch of protected species (SGBYC), 1-4 February 2010, Copenhagen, Denmark. ICES CM 2010/ACOM:25

Imbert G, Laubier L, Malan A, Gaertner JC, Dekeyser I (2007) La thonaille ou courantille volante: rapport final à la région Provence-Alpes-Côte D'azur. Rapport final au Conseil Régional Provence-Alpes-Côte d'Azur. Centre d'Océanologie de Marseille, Marseille

IWC (International Whaling Commission) (2000) Report of the scientific committee. Annex I. Report of the sub-committee on small cetaceans. J Cetacean Res Manag 2(Suppl):235-257

$>$ Jefferson TA, Curry BE (1996) Acoustic methods of reducing or eliminating marine mammal-fishery interactions: Do they work? Ocean Coast Manag 31:41-70

> Johnston DW (2002) The effect of acoustic harassment devices on harbour porpoises (Phocoena phocoena) in the Bay of Fundy, Canada. Biol Conserv 108:113-118

Johnston DW, Woodley TH (1998) A survey of acoustic harassment device (AHD) use in the Bay of Fundy, NB, Canada. Aquat Mamm 24:51-61

> Kastelein RA, Au WWL, De Haan D (2000) Detection distances of bottom-set gillnets by harbour porpoises (Phocoena phocoena) and bottlenose dolphins (Tursiops truncatus). Mar Environ Res 49:359-375

Kasuya T (1985) Fishery-dolphin conflict in the Iki Island area of Japan. In: Beddington J, Beverton RJH, Lavigne DM (eds) Marine mammals and fisheries. George Allen and Unwin, London, p 253-272

Koschinski S, Culik B (1997) Deterring harbour porpoises (Phocoena phocoena) from gillnets: observed reactions to passive reflectors and pingers. Rep Int Whal Comm 47: 659-668

Kraus S (1999) The once and future ping: challenges for the use of acoustic deterrents in fisheries. Mar Technol Soc J 33:90-93

Kraus S, Brault S (1999) A springtime field test of the use of pingers to reduce incidental mortality of harbor porpoises in gillnets. IWC SC/51/SM/WP10, International Whaling Commission, Cambridge

Kraus S, Read A, Anderson E, Baldwin K, Solow A, Spradlin T, Williamson J (1995) A field test of the use of acoustic alarms to reduce incidental mortality of harbor porpoises in gill nets. IWC SC47/SM17, International Whaling Commission, Cambridge

Kraus S, Read A, Anderson E, Baldwin K, Solow A, Spradlin $\mathrm{T}$, Williamson J (1997) Acoustic alarms reduce incidental mortality of porpoises in gill nets. Nature 388:525

Krog C, Larsen F (2007) Anvendelse af pingere i dansk garnfiskeri-overvågning, håndtering og effekt [Use of pingers in Danish gillnet fishery - monitoring, handling and effectiveness]. Report to the European Commission. Danish Ministry of Food Agriculture and Fisheries, Copenhagen (in Danish). http://2.naturerhverv.fvm.dk/Files/ Filer/Fiskeri/Projektdatabase/Kollektive\%20foranstalt ninger/3704-2-05-0120_pingere_i_dansk_garnfiskeri.pdf (accessed 16 Dec 2012)

Laake J, Rugh D, Baraff L (1998) Observations of harbor porpoise in the vicinity of acoustic alarms on a set gill net. NOAA Tech Memo NMFS-AFSC-84

Larsen F (1999) The effect of acoustic alarms on the bycatch of harbour porpoises in the Danish North Sea gill net fishery. IWC SC/51/SM41, International Whaling Commision Cambridge

Larsen F, Hansen JR (2000) On the potential effects of widespread use of pingers in the North Sea. IWC SC/-52/SM28, International Whaling Commission, Cambridge

Larsen F, Krog C (2007) Fishery trials with increased pinger spacing. Paper presented to the Scientific Committee of the International Whaling Commission. IWC SC/59/$\mathrm{SM} 2$, International Whaling Commission, Cambridge

Lauriano G, Fortuna CM, Moltedo G, Notarbartolo di Sciara G (2004) Interaction between common bottlenose dolphin (Tursiops truncatus) and the artisanal fishery in Asinara Island National Park (Sardinia): assessment of catch damage and economic loss. J Cetacean Res Manag 6: 165-173

Lauriano G, Caramanna L, Scarnò M, Andaloro F (2009) An overview of dolphin depredation in Italian artisanal fisheries. J Mar Biol Assoc UK 89:921-929

Le Berre N (2005) Impact de l'introduction de repulsifs acoustiques à cetaces $(<<$ Pingers $>>)$ sur la sécurité et les 
conditions de travail à bord des filayeurs de manchouest. Institut Maritime de Prévention, Lorient

Leeney RH, Berrow S, Mcgrath D, O'Brien J, Cosgrove R, Godley BJ (2007) Effects of pingers on the behaviour of bottlenose dolphins. J Mar Biol Assoc UK 87:129-133

López BD (2006) Interactions between Mediterranean bottlenose dolphins (Tursiops truncatus) and gillnets off Sardinia, Italy. ICES J Mar Sci 63:946-951

López BD, Mariño F (2012) A trial of acoustic harassment device efficacy on free-ranging bottlenose dolphins in Sardinia, Italy. Mar Freshw Behav Physiol 44:197-208

Lunneryd SG (2006) Trials with fishing nets equipped with 'pingers'. Fiskeriverket Swedish Board of Fisheries, Göteborg

Mate BR, Harvey JT (eds) (1987) Acoustical deterrents in marine mammal conflicts with fisheries. Oregon Sea Grant report ORESU-W-86-001, Oregon State University, Corvallis, OR

McPherson GR, Ballam D, Stapley J, Peverell S and others (2004) Acoustic alarms to reduce marine mammal bycatch from gillnets in Queensland waters: optimising the alarm type and spacing. Proc Acoustics 2:1-6

Monteiro-Neto C, Avila FSC, Alves TT Jr, Araujo DS and others (2004) Behavioral responses of Sotalia fluviatilis (Cetacea, Delphinidae) to acoustic pingers, Fortaleza, Brazil. Mar Mamm Sci 20:145-151

Morizur Y, Le Niliot P, Buanic M, Pianalto S (2009) Expérimentations de répulsifs acoustiques commerciaux sur les filets fixes à baudroies en mer d'Iroise. IFREMER, Issyles-Moulineaux. Available at http://archimer.ifremer.fr/ doc/2009/rapport-6864.pdf (accessed 19 Dec 2012)

Murray KT, Read AJ, Solow AR (2000) The use of time/area closures to reduce bycatches of harbour porpoises: lessons from the Gulf of Maine sink gillnet fishery. J Cetacean Res Manag 2:135-141

Northridge S, Tregenza N, Rogan E, Mackey M, Hammond $P$ (1999) A sea trial of acoustic pingers in Celtic Shelf gillnet fisheries. IWC SC/51/SM43, International Whaling Commission, Cambridge

Northridge S, Vernicos D, Raitsos-Exarchopolous D (2003) Net depredation by bottlenose dolphins in the Aegean: first attempts to quantify and to minimise the problem. IWC SC/55/SM25, International Whaling Commission, Cambridge

Northridge S, Kingston A, Murphy S, Mackay A (2008) Monitoring, impact and assessment of marine mammal bycatch. Final report to Defra, Project MF0736, University of St. Andrews, Sea Mammal Research Unit, St. Andrews

Northridge S, Kingston A, Mackay A, Lonergan M (2011) Bycatch of vulnerable species: understanding the process and mitigating the impacts. Final report to Defra, Project MF1003. Available at http://randd.defra.gov. uk/Document.aspx? Document=MF1003-FINALRevised August2011.pdf (accessed 19 Dec 2012)

> Olesiuk PF, Nichol LM, Sowden MJ, Ford JKB (2002) Effect of the sound generated by an acoustic harassment device on the relative abundance and distribution of harbor porpoises (Phocoena phocoena) in Retreat Passage, British Columbia. Mar Mamm Sci 18:843-862

Orphanides CD (2012) New England harbor porpoise bycatch rates during 2010-2012 associated with Consequence Closure Areas. US Department of Commerce, Northeast Fisheries Science Center Reference Document 12-19. Available at www.nefsc.noaa.gov/nefsc/ publications/crd/ (accessed 16 Dec 2012

Palka DL, Rossman MC, Vanatten AS, Orphanides CD (2008) Effect of pingers on harbour porpoise (Phocoena phocoena) bycatch in the US Northeast gillnet fishery. J Cetacean Res Manag 10:217-226

Quick NJ, Middlemas SJ, Armstrong JD (2004) A survey of antipredator controls at marine salmon farms in Scotland. Aquaculture 230:169-180

Read AJ (2008) The looming crisis: interactions between marine mammals and fisheries. J Mammal 89:541-548

Read AJ (2010) Conservation biology. In: Boyd IL, Bowen WD, Iverson SJ (eds) Marine mammal ecology and conservation. A handbook of techniques. Oxford University Press, Oxford, p 340-359

Read AJ, Waples D (2010) A pilot study to test the efficacy of pingers as a deterrent to bottlenose dolphins in the Spanish mackerel gillnet fishery. Bycatch reduction of marine mammals in Mid-Atlantic fisheries. Final report, Project 08-DMM-02, Duke University, Beaufort, SC

Read AJ, Westgate A (1997) Monitoring the movements of harbour porpoises (Phocoena phocoena) with satellite telemetry. Mar Biol 130:315-322

Read AJ, Waples D, Urian KW, Swanner D (2003) Fine-scale behaviour of bottlenose dolphins around gillnets. Proc R Soc Lond B Biol Sci 270:S90-S92

Read AJ, Drinker P, Northridge S (2006) Bycatch of marine mammals in the US and global fisheries. Conserv Biol 20: 163-169

Reeves RR, Read AJ, Notarbartolo-di-Sciara G (2001) Report of the workshop on interactions between dolphins and fisheries in the Mediterranean: evaluation of mitigation alternatives. IWC SC/53/SM3, International Whaling Commission, Cambridge

Richter C, Hood C, Lien J (1999) Mitigation of harbour porpoise bycatch with active acoustic devices in a nonexperimental gillnet fishery. IWC SC/51/SM3, International Whaling Commission, Cambridge

> Rocklin D, Santoni MC, Culioli JM, Tomasini JA, Pelletier D, Mouillot D (2009) Changes in the catch composition of artisanal fisheries attributable to dolphin depredation in a Mediterranean marine reserve. ICES J Mar Sci 66: 699-707

> Rojas-Bracho L, Reeves RR, Jaramillo-Legorreta A (2006) Conservation of the vaquita Phocoena sinus. Mammal Rev 36:179-216

Sagarminaga R, Cañadas A, Brotons JM (2006). Initiatives about fisheries-cetaceans interactions in Spanish Mediterranean waters. IWC SC/58/SM13, International Whaling Commission, Cambridge

Sea Fish Industry Authority (2003) Trial of acoustic deterrents ('porpoise pingers') for prevention of porpoise (Phocoena phocoena) bycatch-Phase 1 Deployment trial. Sea Fish Industry Authority, Hull. Available at www. seafish.org/media/Publications/CR201.pdf (accessed 19 Dec 2012)

Sea Fish Industry Authority (2005) Trial of acoustic deterrent ('porpoise pingers') for prevention of porpoise (Phocoena phocoena) bycatch. Sea Fish Industry Authority, Hull (accessed 16 Dec 2012)

Secchi ER, Wang JR (2002) Assessment of the conservation status of a franciscana (Pontoporia blainvillei) stock in the franciscana management area III following the IUCN red list process. Lat Am J Aquat Mamm 1:183-190

Shapiro AD, Tougaard J, Jørgensen PB, Kyhn LA and others (2009) Transmission loss patterns from acoustic 
harassment and deterrent devices do not always follow geometrical spreading predictions. Mar Mamm Sci 25: 53-67

Slooten E, Fletcher D, Taylor BL (2000) Accounting for uncertainty in risk assessment: case study of Hector's dolphin mortality due to gillnet entanglement. Conserv Biol 14:1264-1270

Slooten E, Dawson SM, Rayment WJ, Childerhouse SJ (2006) A new abundance estimate for Maui's dolphin: What does it mean for managing this critically endangered species? Biol Conserv 128:576-581

SMRU (Sea Mammal Research Unit) (2001) Reduction of porpoise bycatch in bottom set gillnet fisheries. Report to the European Commission Study Contract 97/095, SMRU, University College Cork, Cornish Fish Producer's Organisation, and Irish South and West Fishermen's Organisation, Cork

Stone GS, Kraus S, Hutt A, Martin S, Yoshinaga A, Joy L (1997) Reducing bycatch: Can acoustic pingers keep Hector's dolphins out of fishing nets? Mar Technol Soc J 31:3-7

Stone GS, Cavagnaro L, Hutt A, Kraus S, Baldwin K, Brown $\mathrm{J}$ (2000) Reactions of Hector's dolphins to acoustic gillnet pingers. New Zealand Department of Conservation Technical Report Series, Wellington

Sveegaard S, Teilmann J, Tougaard J, Dietz R, Mouritsen KN, Desportes G, Siebert U (2011) High density areas for harbor porpoises (Phocoena phocoena) identified by satellite tracking. Mar Mamm Sci 27:230-246

Teilmann J, Tougaard J, Miller LA, Kirketerp T, Hansen K, Brando S (2006) Reactions of captive harbor porpoises

Editorial responsibility: William Perrin,

La Jolla, California, USA
(Phocoena phocoena) to pinger-like sounds. Mar Mamm Sci 22:240-260

Trippel EA, Strong MB, Terhune JM, Conway JD (1999) Mitigation of harbour porpoise (Phocoena phocoena) bycatch in the gillnet fishery in the lower Bay of Fundy. Can J Fish Aquat Sci 56:113-123

> Trippel EA, Holy NL, Palka DL, Shepherd TD, Melvin GD, Terhune JM (2003) Nylon barium sulphate gillnet reduces porpoise and seabird mortality. Mar Mamm Sci 19:240-243

van Marlen B (2007) Nephrops and cetacean species selection information and technology. NECESSITY Final Publishable Activity Report. IMARES, Wageningen. Available at http://news.ices.dk/sites/eurepository/Shared Documents/FP6_PROTECT/PROTECT Publishable final report.pdf (accessed 11 Jan 2013)

Waples DM, Thorne LH, Hodge LEW, Burke EK, Urian KW, Read AJ (2013) A field test of acoustic deterrent devices used to reduce interactions between bottlenose dolphins and a coastal gillnet fishery. Biol Conserv 157:165-171

West IF, Molloy J, Donoghue MF, Pugsley C (1999) Seabird and marine mammal bycatch reduction through fishing industry funded research: the New Zealand Conservation Services Levy program. Mar Technol Soc J 33:13-18

> Wilson B, Dill LM (2002) Pacific herring respond to simulated odontocete echolocation sounds. Can J Fish Aquat Sci 59:542-553

Zahri Y, Abid N, Elouamari N, Abdellaoui B (2004) Étude de l'interaction entre le grand dauphin et la pêche à la senne coulissante en Méditerranée marocaine. l'Institut National de Recherche Halieutique (INRH), Nador

Submitted: June 6, 2012; Accepted: September 6, 2012

Proofs received from author(s): December 21, 2012 